\title{
Síndrome de Kallmann: Uma Revisão Histórica, Clínica e Molecular
}

revisão

\author{
ROGÉRIO SILICANI RIBEIRO \\ JuLIo AвUCHAM
}

Unidade de Neuroendocrinologia, Disciplina de Endocrinologia, Departamento de Medicina, Escola Paulista de Medicina,

Universidade Federal de São Paulo, SP, Brasil.
A síndrome de Kallmann (SK) é a associação de hipogonadismo hipogonadotrófico $(\mathrm{HH})$ e anosmia descrita por Maestre de San Juan, em 1856, e caracterizada como condição hereditária por Franz Josef Kallmann, em 1944. Muitos aspectos de sua patogenia, variabilidade fenotípica e genotípica foram desvendados nos últimos 15 anos. Conseqüentemente, tem sido difícil manter-se atualizado frente à rapidez que o conhecimento dessa condição é gerado. Nesta revisão, resgatamos aspectos históricos pouco conhecidos sobre a síndrome e seus descobridores; incorporamos novas descobertas relacionadas à embriogênese dos neurônios olfatórios e produtores de $\mathrm{GnRH}$. Esse processo é fundamental para compreender a associação de hipogonadismo e anosmia; descrevemos a heterogeneidade fenotípica e genotípica, incluindo mutações em cinco genes ( $K A L-1$, FGFR1, PROKR2, PROK2 e NELF). Para cada gene, discutimos a função da proteína codificada na migração e maturação dos neurônios olfatórios e $\mathrm{GnRH}$ a partir de estudos in vitro e modelos experimentais e descrevemos características clínicas dos portadores dessas mutações. (Arq Bras Endocrinol Metab 2008;52/1:8-17)

Descritores: Hipogonadismo hipogonadotrófico; Kallmann; KAL-1; FGFR1; PROKR2; PROK2

\section{ABSTRACT}

Kallmann Syndrome: a Hystorical, Clinical and Molecular Review. Kallmann syndrome (KS), the association of hypogonadotropic hypogonadism and anosmia, was described by Maestre de San Juan in 1856 and characterized as a hereditary condition by Franz Josef Kallmann in 1944. Many aspects such as pathogeny, phenotype and genotype in KS were described in the last fifteen years. The knowledge of this condition has grown fast, making it difficult to update. Here we review historical aspects of this condition and its discoverers and describe new findings regarding the embryogenesis of the olfactory bulb and $\mathrm{GnRH}$ secreting neuronal tracts that are important for understanding the association of hypogonadism and anosmia. Additionally, we describe the phenotypic and genotypic heterogeneity of $K S$, including five related genes (KAL-1, FGFR1, PROKR2, PROK2 e NELF), and discuss the function of each codified protein in migration and maturation of the olfactory and $\mathrm{GnRH}$ neurons, with data from in vitro and in vivo studies. Finally we describe the clinical phenotype of patients carrying these mutations. (Arq Bras Endocrinol Metab 2008;52/1:8-17)

Recebido em 26/04/2007 Aceito em 03/08/2007
Keywords: Hipogonadismo hipogonadotrófico; Kallmann; KAL-1; FGFR1; PROKR2; PROK2 


\section{HISTÓRICO}

A PRIMEIRA DESCRIÇão DA associação de hipogonadismo e anosmia foi feita, em 1856 , pelo médico e professor catedrático de anatomia da Faculdade de Medicina de Granada, Aureliano Maestre de San Juan (1828 - 1890), após a autópsia de um homem de 40 anos, apresentava bulbos olfatórios ausentes e "atrofia congênita" dos testículos e pênis (1). A possibilidade de um distúrbio olfatório foi, então, retrospectivamente investigada "con el objeto de utilizar para la ciencia este notabilísimo caso, traté a toda costa de averiguar algo acerca de las facultades olfatorias de este sujeto, y afortunadamente supe por una hermana del mismo, que su hermano Antonio nunca había tenido conciencia de los cuerpos olorosos, y así que era notable el cómo podía permanecer en cualquier paraje, aunque el olor en aquel punto fuera intolerable" ("com o objetivo de utilizar para a ciência este notável caso, tratei de averiguar algo sobre as faculdades olfatórias desse sujeito e, afortunadamente, soube por sua irmã que seu irmão Antônio nunca havia percebido odores, e assim era notável como podia ficar em qualquer lugar mesmo que o odor local fosse intolerável").

Aureliano Maestre de San Juan (Figura 1) foi o primeiro de uma geração de histologistas espanhóis, dentre os quais se destacou Ramon y Cajal, pai da teoria da plasticidade neuronal. Segundo as memórias escritas por Cajal, “... o boníssimo don Aureliano, a quem tanto nós discípulos venerávamos, sucumbiu depois de um acidente de laboratório..." (com soda cáustica), o que o deixou cego, tendo morrido pobre e esquecido. A descrição inédita da associação de hipogonadismo e anosmia, publicada por Maestre de San Juan na revista espanhola "El Siglo Médico", permaneceu pouco lembrada pela literatura médica (1).

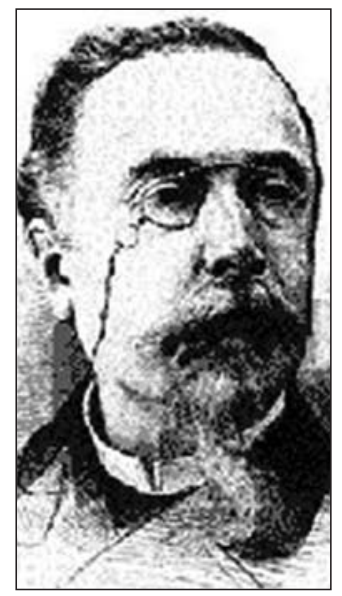

Figura 1. Aureliano Maestre de San Juan (1828 - 1890).
Em 1944, cerca de 80 anos depois da descrição original de Maestre de San Juan, o geneticista alemão Franz Joseph Kallmann (1897 - 1965), um estudioso do caráter hereditário da esquizofrenia e do retardo mental, descreveu três famílias com 12 indivíduos hipogonádicos, dos quais nove eram portadores de anosmia, e dois eram retardados mentais. Kallmann demonstrou o caráter genético da doença, a maior prevalência em homens bem como sua variedade fenotípica (2).

Kallmann defendia a esterilização dos esquizofrênicos como forma de melhorar a raça humana e aprimorar a sociedade. Sua teoria foi usada pelos nazistas como "embasamento científico" para perseguição e extermínio de mais de 200 mil portadores de esquizofrenia e de outras formas de retardo mental, a maioria crianças, em campos de concentração, posteriormente utilizados para o extermínio de judeus e de outras minorias raciais. Ironicamente, Kallmann, filho de mãe judaica, viu-se forçado a migrar para os Estados Unidos para não acabar nos mesmos campos de extermínio criados sob inspiração de sua própria teoria (3). A despeito disso, sua contribuição originou e consagrou o epônimo "síndrome de Kallmann" na literatura médica do pósguerra para descrever a associação de hipogonadismo e anosmia.

Mais recentemente, em 1954, De Morsier cunhou o termo displasia olfato-genital para descrever a coexistência de hipogonadismo e anosmia em 14 indivíduos, porém, ainda hoje, a utilização do epônimo síndrome de Kallmann para descrever essa associação prevalece na literatura (4).

\section{FISIOPATOLOGIA DA ASSOCIAÇÃO DE HIPOGONADISMO E ANOSMIA NA SK}

A fisiopatologia do hipogonadismo na SK começou a ser compreendida após o desenvolvimento das dosagens de gonadotrofinas por radioimunoensaio. Bardin e cols. em 1969, demonstraram que portadores de SK apresentavam baixos níveis de gonadotrofinas e ausência de resposta ao clomifeno, um agonista estrogênico parcial que aumenta a secreção de gonadotrofinas (5). Posteriormente, Naftolin e cols. demonstraram que a infusão endovenosa do hormônio liberador das gonadotrofinas $(\mathrm{GnRH})$ restaurava a secreção de gonadotrofinas em portadores de SK, caracterizando a integridade funcional dos gonadotrofos e a deficiência hipotalâmica de secreção do GnRH (6). 
A anosmia está relacionada à deficiência de $\mathrm{GnRH}$ porque a migração e diferenciação dos neurônios secretores de GnRH dependem da formação do bulbo olfatório (Figura 2). Tanto os neurônios do bulbo olfatório quanto os neurônios secretores de GnRH se originam no epitélio nasal embrionário e migram em direção às meninges, cruzando a placa cribiforme. Logo após, os corpos dos neurônios GnRH dirigem-se para a área pré-óptica do hipotálamo, guiando-se pelas projeções hipotalâmicas dos neurônios do bulbo as quais constituem o trato olfatório $(7,8)$. Assim, defeitos na formação do bulbo e trato olfatórios desorientam a migração e a diferenciação dos neurônios GnRH.

\section{EPIDEMIOLOGIA E QUADRO CLÍNICO}

A prevalência da SKé estimada entre 1:10.000 e 1:80.000 nos homens (9) e cerca de 1:50.000 nas mulheres $(10,11)$. A maioria dos casos é esporádica, mas a síndrome também pode ter caráter familiar. Os homens são mais freqüentemente acometidos do que as mulheres, em uma proporção aproximada de 4:1 nos casos esporádicos e de 2:1 nos casos familiares (12).

A SK é essencialmente caracterizada pela associação de hipogonadismo e anosmia. O hipogonadismo pode ser diagnosticado logo na infância em virtude da criptor- quidia e/ou micropênis ou, mais comumente, na idade puberal em virtude da falta de desenvolvimento dos caracteres sexuais secundários (12). Mais raramente, alguns pacientes apresentarão reversão do hipogonadismo anos após o diagnóstico e início da reposição androgênica. Essa variante fenotípica tem sido denominada SK reversível e caracteriza-se por aumento do volume testicular, normalização dos níveis de testosterona e fertilidade após a suspensão da reposição androgênica (13-21).

O olfato dos portadores da SK pode estar totalmente ausente (anosmia) ou simplesmente reduzido (hiposmia). Os diferentes graus de comprometimento da função olfatória podem ser avaliados por meio da capacidade de reconhecer o odor de uma única substância apresentada em diferentes concentrações, como o álcool, ou da capacidade de discriminar o cheiro de substâncias distintas apresentadas em cápsulas ou cartões que exalam odor após serem abertos ou raspados como no teste de identificação de cheiros da Universidade de Pensilvânia ("UPSIT test”) $(22,23)$. Esses testes geram escores que permitem a quantificação objetiva da função olfatória. Além do comprometimento funcional, os portadores de SK freqüentemente apresentam defeitos morfológicos, como hipotrofia ou ausência do bulbo olfatório uni ou bilateral. A anatomia do bulbo olfatório pode ser mais bem avaliada por ressonância nuclear magnética de encéfalo, em Tl, por intermédio

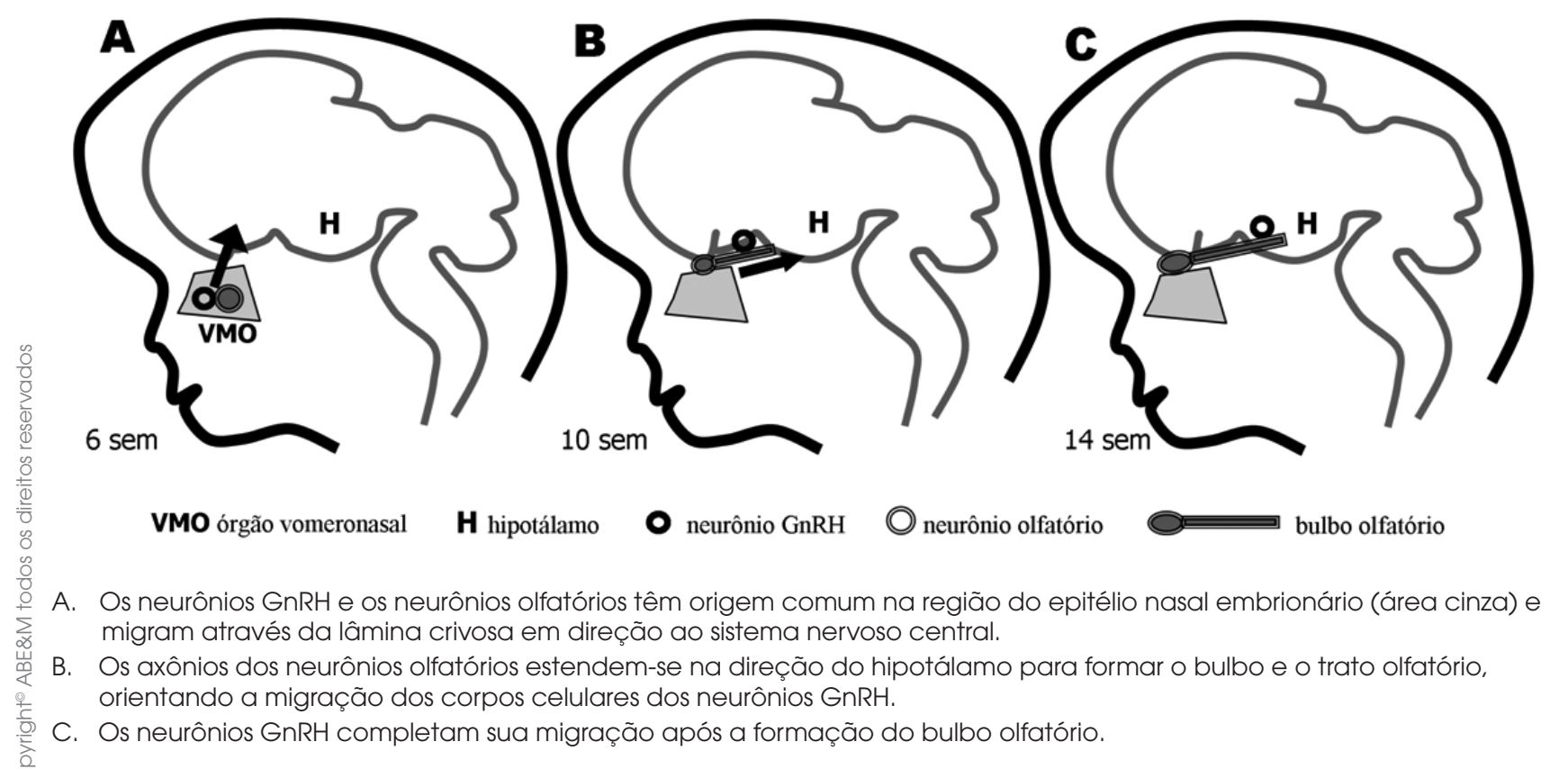

Figura 2. Origem e migração dos neurônios GnRH. 
de cortes coronais finos a partir da parede posterior do seio frontal até o quiasma óptico (24).

Os portadores de SK também podem apresentar outras malformações, como fenda palatina, palato ogival, agenesia renal unilateral ou bilateral (esta incompatível com a vida), sincinesia bimanual (movimentos em espelho), perda auditiva neurossensorial, daltonismo, pé cavo, déficit de aprendizagem, retardo mental, agenesia dental e defeitos da movimentação ocular $(24,25)$.

O fenótipo reprodutivo, olfatório e as manifestações associadas podem ser diferentes em indivíduos pertencentes à mesma família, variando até mesmo entre gêmeos idênticos (26). Parentes de pacientes com SK clássica podem apresentar hipogonadismo isolado, anosmia isolada ou apenas retardo puberal, que apresenta prevalência 12 vezes maior do que na população geral $(12,24,25,27)$.

\section{DIAGNÓSTICO LABORATORIAL DO HIPOGONADISMO NA SK}

O diagnóstico laboratorial do $\mathrm{HH}$ baseia-se na demonstração de níveis baixos de esteróides sexuais (testosterona no homem e estradiol na mulher) associados a níveis normais ou baixos de gonadotrofinas. A dosagem de testosterona total estabelece o diagnóstico na maioria dos casos, porém, quando os valores da testosterona total são limítrofes, pode ser necessário calcular a concentração de testosterona livre por intermédio das dosagens de testosterona total e de SHBG por radioimunoensaio, a qual reflete melhor a fração biologicamente ativa da testosterona (28). Em mulheres, a dosagem do estradiol sérico pode ser normal ou baixa, por isso a amenorréia é um dado mais confiável que essa dosagem no diagnóstico do $\mathrm{HH}$.

A ausência ou redução da resposta das gonadotrofinas ao teste agudo com GnRH confirma o diagnóstico de $\mathrm{HH}$. A pulsatilidade das gonadotrofinas, avaliada por meio de dosagens seriadas, está geralmente ausente ou reduzida na SK, porém alguns indivíduos podem apresentar pulsatilidade normal e resposta das gonadotrofinas ao GnRH também normal $(21,29)$.

\section{GENÉTICA}

A SK familiar apresenta vários padrões de herança, incluindo autossômico dominante, o mais comum, autossômico recessivo e ligado ao $\mathrm{X}$, o que indica o envolvimento de diversos genes (25). Vinte por cento dos casos familiares apresentam mutações em um destes dois genes: KAL-I (SK ligada ao X) e FGFR I (SK autossômica dominante) $(24,30)$. Estudos recentes identificaram três novos genes envolvidos na SK - NELF, PROKR2 e PROK2 - e demonstraram que um paciente pode apresentar mutações em mais de um desses cinco genes (31-33).

\section{GENE KAL-1}

A localização do gene $K A L-1$ em Xp22.3, responsável pela SK ligada ao X, foi determinada por meio de estudos citogenéticos em pacientes com síndrome de genes contíguos os quais também apresentavam hipogonadismo e anosmia associados a grandes deleções na porção distal do braço curto do cromossomo X a partir da posição $\mathrm{Xp} 22.3$, uma região que, na mulher, escapa à inativação (34). Em um feto de 19 semanas com uma deleção cromossômica a partir do Xp22.3, observou-se a ausência de neurônios GnRH no hipotálamo e acúmulo na meninge, em contraste com fetos normais, indicando um defeito migratório (35).

O gene KAL-I (NCBI GeneID: 3730) foi clonado simultaneamente por dois grupos independentes $(36,37)$. O KAL-1 possui 14 exons e codifica a anosmina- 1 , uma glicoproteína associada à matriz extracelular, que é expressa durante o desenvolvimento embrionário no bulbo olfatório, cerebelo, medula, rim e retina. A anosmina-1 apresenta uma região rica em cisteína, seguida por um domínio WAP (whey acidic protein-like four disulfide core), encontrado em diversos inibidores de serina-proteases, e quatro domínios FnIII (tandem fibronectin type III), homólogos aos de moléculas de adesão de células neurais com alta afinidade pelo heparan sulfato (HS) $(38,39)$.

Estudos em cultura organotípica de neurônios olfatórios e secretores de $\mathrm{GnRH}$ demonstraram que a anosmina-l tem ação quimiotáxica e direciona o crescimento dos axônios (alongamento axonal) desses neurônios. Além disso, a anosmina-1 estimula a ramificação e o desenvolvimento de neuritos axonais, o que contribui para o aumento da área de influência neuronal $(38,39)$.

Até o momento, não foram identificados genes homólogos ao KAL-1 em ratos e camundongos, o que tem dificultado a realização de estudos in vivo para avaliar a função da anosmina-1. Em nematódeos Caenorbabiditis elegans transgênicos, a hiperexpressão do gene CeKal, homólogo ao $K A L-1$, induz mudanças no 
direcionamento do crescimento axonal e na ramificação neuronal, além de defeitos morfológicos da cabeça e cauda. A expressão de formas truncadas, sem o domínio WAP, altera o direcionamento axonal do neurônio, enquanto a expressão da forma sem os domínios FnIII altera tanto o direcionamento axonal quanto o padrão de ramificação axonal $(40,41)$.

Recentemente, a expressão de fluoresceína nos neurônios $\mathrm{GnRH}$ de peixes transgênicos Medaka, transparentes durante a embriogênese, permitiu visualizar a origem olfatória dos neurônios $\mathrm{GnRH}$, sua migração até à área pré-óptica ventral e o estabelecimento de conexões com a hipófise anterior. O silenciamento da expressão do gene homólogo ao $K A L-1$ com RNA "antisense" nesses peixes transgênicos impediu a migração e causou acúmulo dos neurônios GnRH no compartimento nasal, além de induzir defeitos na cavidade oral. Esse é o primeiro modelo experimental de SK induzido em um animal vertebrado e certamente permitirá um avanço no entendimento da SK (42).

O rastreamento de mutações no $K A L-1$ em portadores de SK revelou grande heterogeneidade dos defeitos moleculares, incluindo mutações missense e nonsense, mutações de junções de splicing, deleções intragênicas e deleções cromossomais submicroscópicas, localizadas ao longo de praticamente todos os exons do KAL-1. Algumas famílias com SK ligada ao X não apresentam mutações exônicas, o que pode indicar envolvimento de regiões intrônicas desse gene ou a existência de outros genes implicados nessa forma de SK $(24,43,44)$.

O fenótipo da SK nos portadores de mutações do $K A L-1$ nem sempre se correlaciona com o genótipo e pode variar mesmo entre gêmeos monozigóticos que compartilham a mesma mutação (27). A maioria dos portadores de mutações do $K A L-1$ possui comprometimento severo da secreção de gonadotrofinas e quadro clínico evidente já ao nascimento, com criptorquidia em até $75 \%$ dos casos (12). No entanto, dois estudos diferentes descreveram indivíduos com mutação do $K A L-1$ e função gonadal normal $(24,45)$. Recentemente, descrevemos o primeiro caso de SK reversível associado à mutação do KAL-1 (46).

Em mulheres portadoras de mutações do $K A L-1$, o fenótipo é menos severo que nos homens (12). Isso tem sido explicado pela localização do gene $K A L-1$ na região pseudo-autossômica do cromossomo $\mathrm{X}$, a qual escapa da inativação desse cromossomo. Como as mulheres pos- suem duas cópias do X, a mutação em um dos alelos é compensada pelo outro alelo normal (47).

Além da variabilidade do fenótipo reprodutivo, um amplo espectro de defeitos olfatórios, anatômicos e funcionais tem sido encontrado em portadores de mutações no gene $K A L-1$, incluindo hipoplasia e agenesia do bulbo olfatório, uni ou bilateral, hiposmia em graus variados e anosmia. Alguns portadores de mutação do $K A L-1$ podem apresentar bulbos olfatórios e olfato normais (24).

Das outras manifestações associadas à SK, a sincinesia está presente em $75 \%$, e a agenesia renal unilateral, em 30\% dos portadores de SK ligada ao X, mas também podem ser encontradas, com menor prevalência, em outras formas da SK (48). Outras manifestações que podem ocorrer na SK por mutação do $K A L-1$ são surdez neurossensorial, palato em ogiva, pé cavo e anormalidades do movimento ocular (25).

\section{GENE FGFR1}

Assim como na SK ligada ao X, a localização de um dos genes responsáveis pela forma autossômica dominante da SK também baseou-se em estudos de portadores de síndrome de genes contíguos. Utilizando análise de segregação de marcadores polimórficos combinados com estudos de hibridização in situ, Dodé e cols. identificaram mutações na região $8 \mathrm{pll} 1.2 \mathrm{pl}$, que abrangia o gene FGFRI (NCBI GeneID: 2260), em dois indivíduos apresentando $\mathrm{SK}$ associada à esferocitose (30).

Por intermédio do seqüenciamento de todos os exons do gene FGFRl em 129 portadores de SK, foram encontradas mutações em heterozigose em quatro casos familiares e oito casos esporádicos, além de um indivíduo filho de pais consanguíneos apresentar mutação em homozigose. Nos indivíduos homozigóticos, a severidade da SK é maior que em indivíduos heterozigóticos. Esses achados permitiram associar as mutações do FGFRl a uma forma autossômica dominante da SK (30). As diversas mutações identificadas na SK acarretam perda de função do FGFRl (19,33,49-52). Em contraste, uma mutação ativadora do FGFR 1 foi descrita em portadores de uma forma de craniossinostose conhecida como síndrome de Pfeiffer (53).

O gene FGFRl é composto de 18 exons, sendo expresso em múltiplos tecidos embrionários, incluindo esqueleto, ouvido interno e porção rostral do en- 
céfalo (17). O gene FGFRI codifica o receptor tipo 1 do fator de crescimento do fibroblasto (FGFRl), um membro da superfamília dos receptores tirosina quinase. A estrutura do FGFRl consiste de três domínios semelhantes a imunoglobulinas, um domínio acídico, um domínio transmembrana e dois domínios tirosina quinase (54).

O FGFRl é ativado por alguns fatores de crescimento do fibroblasto (FGF). A ligação desses FGFs ao segundo e terceiro domínios semelhante a imunoglobulinas permite a dimerização do receptor e autofosforilação de resíduos tirosina no domínio intracelular (55). Nos neuroblastos $\mathrm{GnRH}$ provenientes do epitélio nasal embrionário humano, o FGF2 liga-se ao FGFRl desencadeando a ativação de vias MAPK (mitogen-activated protein kinase). A presença de glicosaminoglicanos heparan-sulfato (HS) é fundamental para a formação do complexo FGFRlFGF2 e ativação das vias intracelulares (56).

A anosmina-1, proteína codificada pelo KAL-1, interage com o complexo FGFRI-FGF2 como um co-ligante modulador que aumenta a quantidade de HS ligado ao complexo e amplifica a resposta das vias intracelulares (Figura 3). A formação do complexo "anosmina-1FGFR1-FGF2-HS" permite a reorganização do citoes- queleto e o crescimento dos neuritos dos neuroblastos GnRH (56). O envolvimento do FGFRI e da anosmina-l em mecanismos comuns da migração e do desenvolvimento axonal dos neurônios $\mathrm{GnRH}$ explica a semelhança do fenótipo olfatório e reprodutivo da SK associada a mutações dos genes FGFRl e KAL-1 (57).

A importância do FGFRl na formação do bulbo olfatório pode ser demonstrada em camundongos transgênicos com mutação do FGFRI restrita ao telencéfalo. Animais homozigóticos, mas não os heterozigóticos, apresentam aplasia do bulbo olfatório reproduzindo o fenótipo da SK em humanos. Esses animais morrem precocemente após o nascimento, pois a anosmia prejudica a sucção do leite materno (58).

Estudos de rastreamento genético nos portadores de SK identificaram mutações do gene FGFR I em cerca de $6 \%$ a $8 \%$ dos casos esporádicos e até em $20 \%$ dos casos familiares. Assim como nas mutações do $K A L-1$, mutações do FGFRl exibem grande heterogeneidade genotípica, fenótipo familiar variável e $(33,49-52)$ maior severidade do fenótipo reprodutivo em relação aos pacientes com SK sem mutações nesses genes. Assim, uma alta prevalência de criptorquidia e micropênis tem sido observada em homens com mutações do FGFR I (60\% e
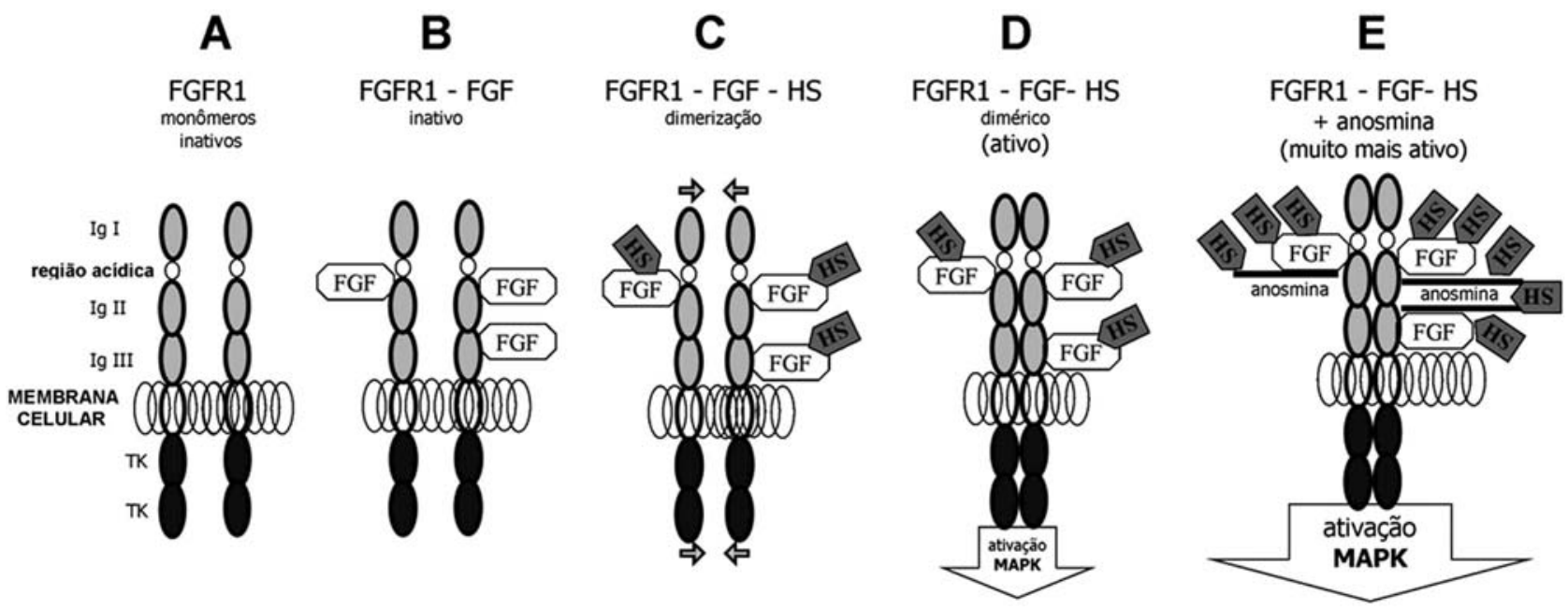

A. O receptor FGFR1 contém três domínios immunoglobulin - like (lg 1, lg2 e lg3) extracelular e dois domínios tirosina quinase e é inativo na forma monomérica.

B. O FGF2 liga-se extensivamente aos domínios D2 e D3.

C. O heparan sulfato (HS) liga-se ao complexo FGFR1-FGF2 possibilitando a dimerização.

D. O complexo FGFR1-FGF2-HS dimerizado autofosforila os resíduos tirosina quinase ativando vias intracelulares MAP quinase.

E. A ligação da anosmina e o complexo FGFR1-FGF2 aumentam a quantidade de HS ligada ao complexo e amplificam a ativação das vias intracelulares.

Figura 3. Ativação do complexo FGFR-1 - FGF2 - HS - anosmina. 
$30 \%$, respectivamente). Por outro lado, fenótipos reprodutivos mais leves, como retardo puberal ou anosmia isolada, são mais comuns em famílias com mutação no FGFRI que no KAL-1 (19). Em famílias com a mesma mutação do FGFR 1, o comprometimento da função gonadal é menos intenso nas mulheres do que nos homens, favorecendo a transmissão materna gene. Isso provavelmente se explica pela existência de duas cópias do gene $K A L-1$ nas mulheres, o que propiciaria maior concentração de anosmina-l nas heterozigotas para o FGFRl, enquanto que os homens, que possuem apenas uma cópia do $K A L-1$, não disporiam desse mecanismo para compensar a haploinsuficiência do FGFRI (57).

Embora não seja possível estabelecer uma correlação precisa entre fenótipo e genótipo na SK, pacientes com mutações do FGFRI freqüentemente apresentam defeitos do palato e agenesia dental não descritos em portadores de mutação no $K A L-1$. Por outro lado, alguns pacientes com mutação no FGFRI apresentam sincinesia bimanual, característica antes tida como exclusiva da SK ligada ao X $(30,52)$.

\section{GENES PROK2 E PROKR2}

A identificação do envolvimento da procineticina (PROK) e seu receptor (PROKR) na SK ocorreu após a demonstração camundongos knock out para o gene da procineticina do tipo 2 (PROK2) apresentarem atrofia do bulbo olfatório e acúmulo de precursores de neurônios GnRH na região rostral da via migratória (38). Em seguida, observaram-se agenesia de bulbo olfatório, atrofia dos órgãos reprodutivos e ausência de neurônios secretores de GnRH no hipotálamo em camundongos com knock out do PROKR2, mas não do PROKR1 (30). Finalmente, mutações nos genes PROK2 e PROKR2 foram encontradas em portadores de SK (32).

O PROK2 (NCBI GeneID: 60675), um gene autossômico, localiza-se na posição 3 pl3, possui 13.403 pares de bases, contendo quatro exons (32), e codifica a procineticina tipo 2 (PROK2), uma proteína de 81 aminoácidos caracterizada pela presença de dez cisteínas conservadas formando cinco pontes disulfídicas e uma seqüência aminoterminal de seis aminoácidos altamente conservada (59). O PROKR2 (NCBI GeneID: 128674) localiza-se na posição 20pl3, possui 1.155 pares de bases, contendo dois exons, e codifica o receptor tipo 2 da procineticina.
A PROK2 pode se ligar a dois subtipos de receptores transmembrana acoplados à proteína $G, P R O K R$ tipos 1 e 2, porém a afinidade da PROK2 para o PROKR2 é maior que a do PROKl. Em humanos, o PROKR 2 distribui-se em glândulas endócrinas - hipófise, testículos, ovário, adrenal e tiróide - e no sistema nervoso central. Além disso, os PROKR 1 e 2 são expressos no trato gastrintestinal (60).

Os receptores PROKR são acoplados a diferentes subtipos de proteína $\mathrm{G}$, incluindo Gq, Gqi e Gs, o que permite ativação de diferentes vias de transdução intracelulares, inclusive a ativação de vias MAPK (60). As PROKs influenciam diversos eventos fisiológicos, como contração intestinal, hiperalgesia, espermatogênese, sobrevivência neuronal, ritmo circadiano, sono, angiogênese, comportamento alimentar e hematopoiese.

Em 192 portadores de SK (144 homens e 48 mulheres), incluindo 38 casos familiares, foram identificadas dez diferentes mutações (9 missense e 1 frameshift) no gene PROKR2 em dez casos esporádicos e em quatro famílias. Essas mutações localizavam-se nas porções intra e extracelular do receptor, bem como nos domínios da transmembrana. Ocorreram em heterozigose (dez casos), homozigose (dois casos) e heterozigose composta (dois casos), sendo que um paciente apresentou uma mutação no PROKR2 e outra no $K A L-1$. Curiosamente, o seqüenciamento de 500 alelos de indivíduos-controle identificou três mutações no PROKR2 (em heterozigose), duas idênticas às encontradas em pacientes com SK (em heterozigose ou em homozigose), além de uma nova mutação não observada na SK.

Nessa mesma população, o seqüenciamento do gene PROK2 identificou quatro diferentes mutações, duas em casos esporádicos e duas em famílias, sendo duas mutações missense, uma frameshift e uma causando uma troca de aminoácidos na seqüência de iniciação de tradução. Nenhuma mutação do gene PROK2 foi identificada no grupo controle (32).

É interessante notar que, além do fenótipo clássico da SK (hipogonadismo associado à anosmia), alguns portadores de mutação nos genes PROKR2 e PROK2 apresentaram hipogonadismo isolado ou anosmia isolada, e nenhum dos portadores de mutação apresentou outras manifestações comuns na SK, como sincinesia bimanual, alterações renais, agenesia dental e defeitos de face ou palato. Um dos portadores de mutação no gene PROK2 apresentava obesidade e alteração do sono, ambos severos. A importância da PROKR2 na regulação do 
ritmo circadiano e no comportamento alimentar já foi demonstrada em animais experimentais (32).

\section{OUTROS GENES E DEFEITOS DIGÊNICOS NA SK}

A identificação do gene NELF(NCBI GeneID 26012) e o reconhecimento de seu envolvimento no $\mathrm{HH}$ ocorreram a partir da análise comparativa da expressão de RNA mensageiro em neurônios GnRH ainda em migração com aqueles que já haviam completado sua migração durante a embriogênese do bulbo olfatório de camundongos. A expressão desse gene ocorria apenas durante a migração neuronal, cessando ao final do processo migratório. No camundongo, o NELF é expresso na superfície celular de neurônios olfatórios no epitélio nasal, sulco olfatório e telencéfalo, demarcando o caminho migratório dos neurônios GnRH durante o período embrionário. A interferência da expressão do gene NELF com RNA "antisense" em cultura de explantes nasais de camundongos reduz o crescimento dos axônios olfatórios e impede a migração dos neurônios GnRH (61). Em humanos, o gene NELF localiza-se na posição $9 \mathrm{q} 34.3$, possui 1.590 pares de bases contendo 16 exons e codifica uma proteína de 530 aminoácidos, com mais de $90 \%$ de homologia em relação aos camundongos.

Uma mutação no gene NELF (missense, sítio de splicing), em heterozigose, foi encontrada em apenas um de 32 pacientes com $\mathrm{HH}$ sem anosmia, mas nenhuma mutação foi observada em 33 pacientes com SK, dos quais 21 eram familiares (34). Em um estudo brasileiro recente, nenhuma mutação desse gene foi identificada em 17 pacientes com $\mathrm{HH}$, incluindo $12 \mathrm{com} \mathrm{SK}(60)$.

Uma mutação do gene NELF e uma outra no FGFRl foram identificadas em uma mesma família, cuja mãe era heterozigota para o NELF e apresentava clinodactilia e síndrome de Duane (síndrome da retração ocular), e o pai, heterozigoto para o gene FGFRl, referia retardo puberal e anosmia. Na prole, apenas o filho, que herdou ambas as mutações, apresentava SK (além de clinodactilia e defeitos de linha média); um outro filho, heterozigoto para a mutação do $N E L F$, era eugonádico e apresentava clinodactilia; um terceiro, heterozigoto para FGFR 1, também eugonádico, apenas apresentava defeitos de linha média $(33,62)$. Em uma outra família, o pai era heterozigoto para duas mutações em genes distintos, uma no GnRHR (gene do receptor do GnRH, R262Q) e a outra no FGFRI
(R470L), tendo tido apenas retardo puberal, e a mãe era heterozigota simples para uma outra mutação no GnRHR (Q106R), sem nenhum fenótipo relacionado. Dos três filhos, duas eram heretozigotas compostas para as mutações do GnRHR e heterozigotas simples para a mutação do FGFRl, e ambas apresentavam HH sem anosmia. Essas famílias ilustram uma interessante possibilidade, a de que defeitos em mais de um gene (oligogênicos) relacionados à formação do sistema GnRH possam determinar a variação fenotípica encontrada em uma mesma família e antes denominada de "penetrância variável" de um defeito supostamente monogênico (31). Assim, nas formas oligogênicas, vários outros genes relacionados ao $\mathrm{HH}$ isolado sem anosmia $(\mathrm{GnRH}$, GnRHR, DAX1, GPR 54, LEPR) poderiam contribuir na expressão fenotípica de pacientes com SK, desde que mutações em genes envolvidos no desenvolvimento do sistema olfatório também estivessem presentes.

\section{REFERÊNCIAS}

1. Maestre de San Juan A. Teratolagia: falta total de los nervios olfactorios con anosmia en un individuo en quien existia una atrofia congenita de los testiculos y miembro viril. El Siglo Medico. 1856; 3:211-21.

2. Kallmann FJ, Schoenfeld WA, Barrera SE. The genetic aspects of primary eunuchoidism. Am J Ment Def. 1944; 158:203-36.

3. Muller-Hill B. Murderous science: elimination by scientific selection of Jews, Gypsies, and others, Germany 1933-1945. New York: Oxford University Press. English translation by G. Fraser, 1988.

4. De Morsier G. [Studies in cranio-encephalic dysraphia. I. Agenesia of the olfactory lobe (lateral telencephaloschisis) and of the callous and anterior commissures (median telencephaloschisis); olfacto-genital dysplasia.]. Schweiz Arch Neurol Psychiatr. 1954; 74(1-2):309-61.

5. Bardin CW, Ross GT, Rifkind AB, Cargille CM, Lipsett MB. Studies of the pituitary-Leydig cell axis in young men with hypogonadotropic hypogonadism and hyposmia: comparison with normal men, prepuberal boys, and hypopituitary patients. J Clin Invest. 1969; 48(11):2046-56.

6. Naftolin F, Harris GW, Bobrow M. Effect of purified luteinizing hormone releasing factor on normal and hypogonadotrophic anosmic men. Nature. 1971; 232(5311):496-7.

7. Schwanzel-Fukuda M, Jorgenson KL, Bergen HT, Weesner GD, Pfaff DW. Biology of normal luteinizing hormone-releasing hormone neurons during and after their migration from olfactory placode. Endocr Rev. 1992; 13(4):623-34.

8. Wray S. Development of luteinizing hormone releasing hormone neurones. J Neuroendocrinol. 2001; 13(1):3-11.

9. Fromantin M, Gineste J, Didier A, Rouvier J. [Impuberism and hypogonadism at induction into military service. Statistical study]. Probl Actuels Endocrinol Nutr. 1973; 16:179-99.

10. Pawlowitzki IH, Diekstall P, Schadel A, Miny P. Estimating frequency of Kallmann syndrome among hypogonadic and among anosmic patients. Am J Med Genet. 1987; 26(2):473-9. 
11. Filippi G. Klinefelter's syndrome in Sardinia. Clinical report of 265 hypogonadic males detected at the time of military checkup. Clin Genet. 1986; 30(4):276-84.

12. Seminara SB, Hayes FJ, Crowley WF Jr. Gonadotropin-releasing hormone deficiency in the human (idiopathic hypogonadotropic hypogonadism and Kallmann's syndrome): pathophysiological and genetic considerations. Endocr Rev. 1998; 19(5):521-39.

13. Bauman A. Markedly delayed puberty or Kallmann's syndrome variant. J Androl. 1986; 7(4):224-7.

14. Rogol AD, Mittal KK, White BJ, McGinniss MH, Lieblich JM, Rosen SW. HLA-compatible paternity in two "fertile eunuchs" with congenital hypogonadotropic hypogonadism and anosmia (the Kallmann syndrome). J Clin Endocrinol Metab. 1980; 51(2):275-9.

15. Rezvani I, DiGeorge AM, Rutano J, Snyder PJ. Delayed Puberty and anosmia; coincidence or Kallmann variant? [Abstract]. Pediatric Research. 1975; 9:224.

16. Quinton R, Cheow HK, Tymms DJ, Bouloux PM, Wu FC, Jacobs HS. Kallmann's syndrome: is it always for life? Clin Endocrinol (Oxf). 1999; 50(4):481-5.

17. Rowe RC, Schroeder ML, Faiman C. Testosterone-induced fertility in a patient with previously untreated Kallmann's syndrome. Fertil Steril. 1983; 40(3):400-1.

18. Bagatell CJ, Paulsen CA, Bremner WJ. Preservation of fertility despite subnormal gonadotropin and testosterone levels after cessation of pulsatile gonadotropin-releasing hormone therapy in a man with Kallmann's syndrome. Fertil Steril. 1994; 61(2):392-4.

19. Pitteloud N, Acierno JS Jr, Meysing AU, Dwyer AA, Hayes FJ, Crowley WF Jr. Reversible kallmann syndrome, delayed puberty, and isolated anosmia occurring in a single family with a mutation in the fibroblast growth factor receptor 1 gene. J Clin Endocrinol Metab. 2005; 90(3):1317-22.

20. Quinton R, Duke VM, Robertson A, Kirk JM, Matfin G, de Zoysa PA et al. Idiopathic gonadotrophin deficiency: genetic questions addressed through phenotypic characterization. Clin Endocrinol (Oxf). 2001; 55(2):163-74.

21. Kadva A, Di WL, Djahanbakhch O, Monson J, Silman R. Evidence for the Bauman variant in Kallmann's syndrome. Clin Endocrinol (Oxf). 1996; 44(1):103-10.

22. Davidson TM, Murphy C. Rapid clinical evaluation of anosmia. The alcohol sniff test. Arch Otolaryngol Head Neck Surg. 1997; 123(6):591-4.

23. Doty RL, Shaman P, Kimmelman CP, Dann MS. University of Pennsylvania Smell Identification Test: a rapid quantitative olfactory function test for the clinic. Laryngoscope. 1984; 94(2 Pt 1):176-8.

24. Quinton R, Duke VM, de Zoysa PA, Platts AD, Valentine A, Kendall $B$ et al. The neuroradiology of Kallmann's syndrome: a genotypic and phenotypic analysis. J Clin Endocrinol Metab. 1996; 81(8):3010-7.

25. Waldstreicher J, Seminara SB, Jameson JL, Geyer A, Nachtigall LB, Boepple PA et al. The genetic and clinical heterogeneity of gonadotropin-releasing hormone deficiency in the human. J Clin Endocrinol Metab. 1996; 81(12):4388-95.

26. Hipkin LJ, Casson IF, Davis JC. Identical twins discordant for Kallmann's syndrome. J Med Genet. 1990; 27(3):198-9.

27. Matsuo T, Okamoto S, Izumi Y, Hosokawa A, Takegawa T, Fukui H et al. A novel mutation of the KAL1 gene in monozygotic twins with Kallmann syndrome. Eur J Endocrinol. 2000; 143(6):783-7.
28. Vermeulen A, Verdonck L, Kaufman JM. A critical evaluation of simple methods for the estimation of free testosterone in serum. J Clin Endocrinol Metab. 1999; 84(10):3666-72.

29. Chryssikopoulos A, Gregoriou O, Vitoratos N, Rizos D, Papadias $\mathrm{K}$. The predictive value of double $\mathrm{Gn}-\mathrm{RH}$ provocation test in unprimed $\mathrm{Gn}-\mathrm{RH}$-primed and steroid-primed female patients with Kallmann's syndrome. Int J Fertil Womens Med. 1998; 43(6):291-9.

30. Dode C, Levilliers J, Dupont JM, De Paepe A, Le Du N, SoussiYanicostas $\mathrm{N}$ et al. Loss-of-function mutations in FGFR1 cause autosomal dominant Kallmann syndrome. Nat Genet. 2003; 33(4):463-5.

31. Miura K, Acierno JS Jr, Seminara SB. Characterization of the human nasal embryonic LHRH factor gene, NELF, and a mutation screening among 65 patients with idiopathic hypogonadotropic hypogonadism (IHH). J Hum Genet. 2004; 49(5):265-8.

32. Dode C, Teixeira L, Levilliers J Bouchard $P$, Kottler ML, Lespinasse $\mathrm{J}$ et al. Kallmann syndrome: mutations in the genes encoding prokineticin-2 and prokineticin receptor-2. PLoS Genet. 2006; 2(10):e175.

33. Pitteloud N, Quinton R, Pearce S, Raivio T, Acierno J, Dwyer A et al. Digenic mutations account for variable phenotypes in idiopathic hypogonadotropic hypogonadism. J Clin Invest. 2007; 117(2):457-63.

34. Meitinger T, Heye B, Petit C, Levilliers J, Golla A, Moraine C et al. Definitive localization of $X$-linked Kallman syndrome (hypogonadotropic hypogonadism and anosmia) to Xp22.3: close linkage to the hypervariable repeat sequence CRI-S232. Am J Hum Genet. 1990; 47(4):664-9.

35. Schwanzel-Fukuda M, Bick D, Pfaff DW. Luteinizing hormonereleasing hormone ( $\mathrm{LHRH}$ )-expressing cells do not migrate normally in an inherited hypogonadal (Kallmann) syndrome. Brain Res Mol Brain Res. 1989; 6(4):311-26.

36. Franco B, Guioli S, Pragliola A, Incerti B, Bardoni B, Tonlorenzi $R$ et al. A gene deleted in Kallmann's syndrome shares homology with neural cell adhesion and axonal path-finding molecules. Nature. 1991; 353(6344):529-36.

37. Legouis R, Hardelin JP, Levilliers J, Claverie JM, Compain S, Wunderle $\mathrm{V}$ et al. The candidate gene for the X-linked Kallmann syndrome encodes a protein related to adhesion molecules. Cell. 1991; 67(2):423-35.

38. Soussi-Yanicostas N, Faivre-Sarrailh C, Hardelin JP, Levilliers J, Rougon G, Petit C. Anosmin-1 underlying the $X$ chromosome-linked Kallmann syndrome is an adhesion molecule that can modulate neurite growth in a cell-type specific manner. J Cell Sci. 1998; 111( Pt 19):2953-65.

39. Soussi-Yanicostas N, de Castro F, Julliard AK, Perfettini I, Chedotal A, Petit C. Anosmin-1, defective in the X-linked form of Kallmann syndrome, promotes axonal branch formation from olfactory bulb output neurons. Cell. 2002; 109(2):217-28.

40. Rugarli El, Di Schiavi E, Hilliard MA, Arbucci S, Ghezzi C, Facciolli $A$ et al. The Kallmann syndrome gene homolog in C. elegans is involved in epidermal morphogenesis and neurite branching. Development. 2002; 129(5):1283-94.

41. Bulow HE, Berry KL, Topper LH, Peles E, Hobert O. Heparan sulfate proteoglycan-dependent induction of axon branching and axon misrouting by the Kallmann syndrome gene kal-1. Proc Natl Acad Sci U S A. 2002; 99(9):6346-51.

42. Okubo K, Sakai F, Lau EL, Yoshizaki G, Takeuchi Y, Naruse K et al. Forebrain gonadotropin-releasing hormone neuronal development: insights from transgenic medaka and the relevance to X-linked Kallmann syndrome. Endocrinology. 2006; 147(3):1076-84. 
43. Hardelin JP, Levilliers J, Blanchard S, Carel JC, Leutenegger M, Pinard-Bertelletto JP et al. Heterogeneity in the mutations responsible for $\mathrm{X}$ chromosome-linked Kallmann syndrome. Hum Mol Genet. 1993; 2(4):373-7.

44. Oliveira LM, Seminara SB, Beranova M, Hayes FJ, Valkenburgh SB, Schipani E et al. The importance of autosomal genes in Kallmann syndrome: genotype-phenotype correlations and neuroendocrine characteristics. J Clin Endocrinol Metab. 2001; 86(4):1532-8.

45. Parenti G, Rizzolo MG, Ghezzi M, Di Maio S, Sperandeo MP, Incerti $B$ et al. Variable penetrance of hypogonadism in a sibship with Kallmann syndrome due to a deletion of the KAL gene. Am J Med Genet. 1995; 57(3):476-8.

46. Ribeiro RS, Vieira TCA, Abucham J. Reversible Kallmann syndrome: report of the first case with a KAL-1 mutation and literature review. Eur J Endocrinol. 2007; 156(3):285-9.

47. Dode C, Hardelin JP. Kallmann syndrome: fibroblast growth factor signaling insufficiency? J Mol Med. 2004;82(11):725-34.

48. Mayston MJ, Harrison LM, Quinton R, Stephens JA, Krams M, Bouloux PM. Mirror movements in X-linked Kallmann's syndrome. I. A neurophysiological study. Brain. 1997; 120 (Pt 7):1199-216.

49. Albuisson J, Pecheux C, Carel JC, Lacombe D, Leheup B, Lapuzina $P$ et al. Kallmann syndrome: 14 novel mutations in KAL1 and FGFR1 (KAL2). Hum Mutat. 2005; 25(1):98-9.

50. Sato N, Katsumata N, Kagami M, Hasegawa T, Hori N, Kawakita $S$ et al. Clinical assessment and mutation analysis of Kallmann syndrome 1 (KAL1) and fibroblast growth factor receptor 1 (FGFR1, or KAL2) in five families and 18 sporadic patients. $J$ Clin Endocrinol Metab. 2004; 89(3):1079-88.

51. Pitteloud N, Acierno JS Jr, Meysing A, Dwyer AA, Hayes FJ and Crowley Jr WF. Mutations in fibroblast growth factor receptor 1 cause both Kallmann syndrome and normosmic idiopathic hypogonadotropic hypogonadism. Proc Natl Acad Sci U S A. 2006; 103(16):6281-6.

52. Trarbach EB, Frade Costa EM, Versiani B, de Castro M, Matias Baptista MT, Garmes HMB et al. Novel fibroblast growth factor receptor 1 mutations in patients with congenital hypogonadotropic hypogonadism with and without anosmia. J Clin Endocrinol Metab. 2006; 91(10):4006-12.

53. Muenke M, Schell U, Hehr A, Robin NH, Losken HW, Schinzel A et al. A common mutation in the fibroblast growth factor receptor 1 gene in Pfeiffer syndrome. Nat Genet. 1994; 8(3):269-74.
54. Groth C, Lardelli M. The structure and function of vertebrate fibroblast growth factor receptor 1. Int J Dev Biol. 2002; 46(4):393-400.

55. Simon MA. Receptor tyrosine kinases: specific outcomes from general signals. Cell. 2000; 103(1):13-5.

56. Gonzalez-Martinez D, Kim SH, Hu Y, Guimond S, Schofield J, Winyard $\mathrm{P}$ et al. Anosmin-1 modulates fibroblast growth factor receptor 1 signaling in human gonadotropin-releasing hormone olfactory neuroblasts through a heparan sulfate-dependent mechanism. J Neurosci. 2004; 24(46):10384-92.

57. Gonzalez-Martinez D, Hu Y, Bouloux PM. Ontogeny of GnRH and olfactory neuronal systems in man: novel insights from the investigation of inherited forms of Kallmann's syndrome. Front Neuroendocrinol. 2004; 25(2):108-30.

58. Hebert JM, Lin M, Partanen J, Rossant J, McConnell SK. FGF signaling through FGFR1 is required for olfactory bulb morphogenesis. Development. 2003; 130(6):1101-11.

59. Li M, Bullock CM, Knauer DJ, Ehlert FJ, Zhou QY. Identification of two prokineticin cDNAs: recombinant proteins potently contract gastrointestinal smooth muscle. Mol Pharmacol. 2001; 59(4):692-8.

60. Lin DC, Bullock CM, Ehlert FJ, Chen JL, Tian H, Zhou QY. Identification and molecular characterization of two closely related $\mathrm{G}$ protein-coupled receptors activated by prokineticins/endocrine gland vascular endothelial growth factor. J Biol Chem. 2002; 277(22):19276-80.

61. Kramer PR, Wray S. Nasal embryonic LHRH factor (NELF) expression within the CNS and PNS of the rodent. Brain Res Gene Expr Patterns. 2001; 1(1):23-6.

62. Trarbach EB, Baptista MT, Garmes HM, Hackel C. Molecular analysis of KAL-1, GnRH-R, NELF and EBF2 genes in a series of Kallmann syndrome and normosmic hypogonadotropic hypogonadism patients. J Endocrinol. 2005; 187(3):361-8.

\section{Endereço para correspondência:}

Julio Abucham

Disciplina de Endocrinologia, Escola Paulista de Medicina

Rua Pedro de Toledo, 910

04039-002 São Paulo, SP

E-mail: julioabucham@uol.com.br 